\title{
CLINICAL STUDY OF POSTOPERATIVE PULMONARY COMPLICATIONS FOLLOWING ABDOMINAL OPERATIONS IN A TERTIARY CARE CENTRE
}

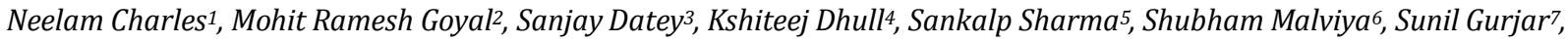 \\ Raunak Gupta ${ }^{8}$
}

1 Professor, Department of General Surgery, Sri Aurobindo Medical College and Postgraduate Institute, Indore, Madhya Pradesh. ${ }^{2}$ Resident, Department of General Surgery, Sri Aurobindo Medical College and Postgraduate Institute, Indore, Madhya Pradesh. 3 Professor, Department of General Surgery, Sri Aurobindo Medical College and Postgraduate Institute, Indore, Madhya Pradesh. ${ }^{4}$ Resident, Department of General Surgery, Sri Aurobindo Medical College and Postgraduate Institute, Indore, Madhya Pradesh. ${ }^{5}$ Resident, Department of General Surgery, Sri Aurobindo Medical College and Postgraduate Institute, Indore, Madhya Pradesh. ${ }^{6}$ Resident, Department of General Surgery, Sri Aurobindo Medical College and Postgraduate Institute, Indore, Madhya Pradesh. ${ }^{7}$ Resident, Department of General Surgery, Sri Aurobindo Medical College and Postgraduate Institute, Indore, Madhya Pradesh. ${ }^{8}$ Resident, Department of General Surgery, Sri Aurobindo Medical College and Postgraduate Institute, Indore, Madhya Pradesh. ABSTRACT

\section{BACKGROUND}

Abdominal surgery is a challenging field, as the outcome of any operation depends on various factors. Postoperative pulmonary complications lead to prolonged morbidity. Many of patients with postoperative pulmonary complication require ventilatory support for a prolonged period.

\section{MATERIALS AND METHODS}

This is a prospective observational study of 18 months on patients diagnosed of pulmonary complications following abdominal surgeries in a tertiary care centre.

\section{RESULTS}

In our study, postoperative pulmonary complications were more common after emergency abdominal operations with $80.48 \%$ in old age patients with maximum being between the age group of 65 - 74 years. Eighty-two patients showed postoperative pulmonary complications, out of which 29 patients required ventilatory support. Nine patients needed additional intervention like chest tube drainage and tracheostomy.

\section{CONCLUSION}

Postoperative pulmonary complications are the most challenging complications a surgeon has to deal with after abdominal surgeries. Postoperative pulmonary complications depend on many factors related to the patient, surgeon and environment. The most common pulmonary complications after abdominal surgeries are pneumonia, atelectasis, pleural effusion, ARDS and lung collapse. Postoperative pulmonary complications increase the morbidity and mortality significantly and add to the economical burden of the patient and his family due to a prolonged stay in the hospital.

\section{KEYWORDS}

Postoperative Pulmonary Complications, Ventilator Support, Postoperative Pneumonia.

HOW TO CITE THIS ARTICLE: Charles N, Goyal MR, Datey S, et al. Clinical study of postoperative pulmonary complications following abdominal operations in a tertiary care centre. J. Evolution Med. Dent. Sci. 2018;7(15):1833-1836, D0I: $10.14260 /$ jemds/2018/414

\section{BACKGROUND}

Abdominal surgery is a challenging field as the outcome of any operation depends on various factors. A patient with a meticulously done gastrectomy can have prolonged morbidity due to postoperative pulmonary complication rather than the surgical trauma. With the advancement in the field of anaesthesia and preoperative pulmonary care in planned operations, pulmonary complications are scarcely seen.

'Financial or Other Competing Interest': None.

Submission 28-02-2018, Peer Review 24-03-2018,

Acceptance 30-03-2018, Published 09-04-2018.

Corresponding Author:

Dr. Mohit Ramesh Goyal,

Resident, Department of General Surgery,

Sri Aurobindo Medical College and

Postgraduate Institute, Indore,

Madhya Pradesh.

E-mail: mg171991@gmail.com

DOI: $10.14260 /$ jemds $/ 2018 / 414$

\section{(c) $(1)(5)$}

Patients of emergency abdominal surgeries are not free from pulmonary complications, as they are not well prepared. Postoperative pulmonary complications following emergency abdominal surgery mainly occur due to two main reasons-

a. Pre-existing pulmonary complaints and co-morbidities.

b. Surgical trauma in addition to the abdominal pathology.

Many of the patients with postoperative pulmonary complications require ventilatory support for a prolonged period, although it definitely helps in improving the outcome of the abdominal surgeries, but it adds to overall expenses.

In this observational study, we have tried to analyse the postoperative pulmonary complications following abdominal operations.

\section{MATERIALS AND METHODS}

We have conducted this prospective observational study of pulmonary complications in patients who underwent abdominal operations in tertiary care centre during a period of one and a half years. Patients fulfilling the inclusion criteria 
were thoroughly examined. These patients were followed closely during their stay in hospital. The collected data was further analysed with the help of biostatistician using appropriate statistical methods. All the cases with confirmed diagnosis of pulmonary complications following surgeries fitting according to the inclusion and exclusion criteria were included into the study analysis.

\section{Inclusion Criteria}

1. All patients with pulmonary complications after abdominal operations.

2. All such patients who are consenting above 16 years for participation in the study.

\section{RESULTS}

In this study various factors responsible for determining the outcome of the patient following abdominal surgeries were studied and a total of 82 patients suffered from postoperative pulmonary complications in the time duration of one and a half years. Table 1 depicts that postoperative pulmonary complications were more common after emergency abdominal operations with $80.48 \%$ of patients as compared to the patients operated electively.

\begin{tabular}{|c|c|c|}
\hline Nature of Operation & Total Number (n= 82) & $\mathbf{( \% )}$ \\
\hline Emergency & 66 & 80.48 \\
\hline Elective & 16 & 19.51 \\
\hline \multicolumn{2}{|c|}{ Table 1. Distribution as per Nature of Operation } \\
\hline
\end{tabular}

Table No. 2 shows that the highest incidence of postoperative pulmonary complications were seen in old age with maximum being between the age group of $65-74$ years. Our study also shows that younger patients did not have significant number of postoperative pulmonary complications $(13 / 82$ of age group 15 - 34). The mean age showing pulmonary complication is 54 years and median is 55 years.

\begin{tabular}{|c|c|c|}
\hline Age Group & Number (n= 82) & Percentage (\%) \\
\hline $15-24$ & 5 & 6.09 \\
\hline $25-34$ & 8 & 9.75 \\
\hline $35-44$ & 13 & 15.85 \\
\hline $45-54$ & 9 & 10.97 \\
\hline $55-64$ & 17 & 20.73 \\
\hline $65-74$ & 22 & 26.82 \\
\hline $75-84$ & 6 & 7.31 \\
\hline $85-94$ & 2 & 2.43 \\
\hline \multicolumn{2}{|c|}{ Table 2. Distribution as per Age Group } \\
\hline \multicolumn{3}{|r}{} \\
\hline
\end{tabular}

Table No. 3 shows the relation between the duration of surgery with the postoperative pulmonary complications. As the duration increased, the chances of pulmonary complications also increased.

\begin{tabular}{|c|c|}
\hline Duration in Hours & Number \\
\hline $1-2$ & 24 \\
\hline $2-3$ & 53 \\
\hline $3-4$ & 2 \\
\hline $4-5$ & - \\
\hline $5-6$ & 2 \\
\hline$>6$ & 1 \\
\hline \multicolumn{2}{|c|}{ Table 3. Distribution as per Duration of Surgery } \\
\hline
\end{tabular}

Table No. 4 depicts that the maximum postoperative pulmonary complications were seen in patients who underwent major abdominal surgeries showing that the surgical insult in a patient also affects the postoperative pulmonary complications in the patients.

\begin{tabular}{|c|c|c|}
\hline Type of Operation & Total Number (n= 82) & (\%) \\
\hline Supra Major & 6 & 7.31 \\
\hline Major & 69 & 84.14 \\
\hline Intermediate & 7 & 8.53 \\
\hline \multicolumn{2}{|c|}{ Table 4. Distribution as per Type of Surgery } \\
\hline
\end{tabular}

The above table shows that of all the 82 patients, seventy three percent belonged to ASA Grade II and twenty five percent belonged to ASA Grade III. Our study had only 1 patient of ASA Grade IV, who had postoperative pulmonary complication.

\begin{tabular}{|c|c|c|}
\hline ASA Category & Total Number $(\mathbf{n = ~ 8 2 )}$ & $\mathbf{( \% )}$ \\
\hline I & - & - \\
\hline II & 60 & 73.17 \\
\hline III & 21 & 25.60 \\
\hline IV & 1 & 1.21 \\
\hline \multicolumn{2}{|c|}{ Table 5. Distribution as per ASA Category } \\
\hline
\end{tabular}

Table 6 shows that in this study, pulmonary complications were seen more in patients who had nasogastric tube in situ for 5 - 10 days.

\begin{tabular}{|c|c|}
\hline Days of Nasogastric Tube & Number \\
\hline $1-4$ & 14 \\
\hline $5-10$ & 65 \\
\hline $11-14$ & 1 \\
\hline $15-20$ & 1 \\
\hline $21-24$ & - \\
\hline $25-30$ & 1 \\
\hline Table 6. Distribution as per Nasogastric Tube In Situ \\
\hline
\end{tabular}

Table 7 shows that pulmonary complications following abdominal operations were seen more in patients who were smokers with a percentage of $63.41 \%$.

\begin{tabular}{|c|c|c|}
\hline Smoking History & Total Number (n= 82) & $\mathbf{( \% )}$ \\
\hline Smoker & 52 & 63.41 \\
\hline Non-Smoker & 30 & 36.58 \\
\hline \multicolumn{2}{|c|}{ Table 7. Distribution as per H/O Smoking } \\
\hline
\end{tabular}

Table No. 8 depicts the nature of pulmonary complications following abdominal surgeries. The most common pulmonary complication following abdominal surgeries was pneumonia (31.76\%). The second most common complication was atelectasis, which was seen in 24 patients. The other complications were pleural effusion and lung collapse.

\begin{tabular}{|c|c|c|}
\hline Chest X-Ray Findings & Number & (\%) \\
\hline Atelectasis & 24 & 28.23 \\
\hline Pneumonia & 27 & 31.76 \\
\hline Lung Collapse & 13 & 15.29 \\
\hline Pleural Effusion & 21 & 24.70 \\
\hline Total & $\mathbf{8 5}$ & \\
\hline \multicolumn{2}{|c}{ Table 8. Chest X-Ray Finding } \\
\hline
\end{tabular}


Out of eighty two patients of pulmonary complications in our study, twenty nine (35.36\%) patients required ventilatory support in the postoperative period. Out of these twenty nine patients, twenty one patients died in spite of all the resuscitative measures. Nineteen patients who required ventilatory support were smokers. Additional interventions were done in $15.25 \%$ of patients.

Twenty two patients requiring ventilatory support underwent major abdominal operations. Four out of twenty nine patients were operated in routine hours and twenty five patients were operated in emergency.

\section{DISCUSSION}

Age is one of the major criteria, which plays an important role in development of postoperative pulmonary complications after abdominal operations. In our study, maximum number of pulmonary complications were seen in the age group operated $55-74$ years. In a study conducted by Livia Goreth GalvaoSerejo et al ${ }^{1}$ showed that postoperative pulmonary complications were more prevalent above the age of 50 years with a percentage of $48 \%$. In our study, there is higher incidence of postoperative pulmonary complication with mean age group of 54 years. Another study conducted by Luiz Joia Neto et al, the age group of 65 years showed maximum postoperative pulmonary complications with the percentage of $23.3 \%$.

In our study 82 patients had postoperative pulmonary complications, out of which $80.48 \%$ of patients operated during emergency hours had postoperative pulmonary complications. Emergency settings do not allow the surgeons to make necessary recruitments for improving the patient's morbidity. When we studied the agronomics of surgery and its possible complications, a debatable issue was the possibility of significant differences between complications following elective surgery and those following emergency surgery. Some studies of postoperative respiratory complications incidence have demonstrated that such differences exist since patients submitted to elective surgery were from a clinical standpoint better prepared for the operation. In the study conducted by Luiz Joia Neto et al ${ }^{1}$ found no statistically significant difference between patients submitted to elective surgery and those submitted to emergency surgery. In a study conducted by Zewditu Abdissa Denu et $\mathrm{al}^{2}$ showed that there was an increased incidence of postoperative pulmonary complications in patients who underwent emergency abdominal operations with a percentage of $56 \% .1,2$

Prolonged surgery was also identified as significant predictors of postoperative pulmonary complications and it is well supported by review of literature. In fact multivariate analyses have found prolonged surgery, ranging from 3 to 4 hours to be an independent predictor of postoperative pulmonary complications. In our study, the most number of pulmonary complications was seen with patients whose surgical duration was between 2 - 3 hrs. 3,4

Presence of nasogastric tube during abdominal operations is required, as it helps in causing selective decompression of the digestive tract. It impairs the cough reflex and provides a more direct pathway for oropharyngeal bacteria to lungs, thus increasing respiratory tract infections. In our study, all patients who underwent abdominal operations had nasogastric tube in situ. $79.26 \%$ of patients who developed pulmonary complications had nasogastric tube in situ for around 5 - 10 days. Nelson et al ${ }^{5}$ conducted a meta-analysis of 24 studies that compared routine nasogastric tube use in abdominal surgery with selective use based on symptoms or abdominal distention. They found that routine use was associated with a significant increase in postoperative pulmonary complications.5,6

Cigarette smoking is a significant preoperative risk factor. The effect of this is primarily related to chronic lung disease. Cessation of cigarette smoking for 48 hrs. before surgery include an expected reduction in cough, reduction in lower airway pathogens, decreases carboxyhaemoglobin levels to normal, abolishes the stimulant effect of nicotine on cardiovascular system and improves respiratory ciliary beating. In our study that pulmonary complications following abdominal operations were seen more in patients who were smokers with a percentage of $63.41 \%$. In the study conducted by Jo Ann Brooks-Brunn, 7 the patient who developed postoperative pulmonary complications were smokers with a significant ' $p$ ' value of $<0.001 .7,8,9$

Postoperative pneumonia is the most common pulmonary complication. In our study patients who had postoperative pulmonary complications $31.27 \%$ of patients suffered from pneumonia, $28.23 \%$ of people suffered from atelectasis and $24.70 \%$ of people suffered from pleural effusion. This is consistent with the study conducted by Kanat et al,10 Gerard et al and Brook ${ }^{7}$ where pneumonia was the leading postoperative pulmonary complication in their study. According to the data in the literature, the incidence of pneumonia in adults submitted to general surgery ranges from $18 \%$ to $68 \%$. The incidence of pneumonia in patients over 65 years submitted to general surgery has been reported to be $56 \% .5,10,7,11,6$

In our study, 29 patients needed ventilator support in the management of postoperative pulmonary complications. There are many reasons for the requirement of ventilator support after abdominal operations, for e.g. Shock; ARDS; MODS. Postoperative pulmonary complications like pneumonia; atelectasis; pleural effusion generally do not require ventilatory support unless it causes severe decrease in the respiratory function causing severe hypoxia. There are various reasons for developing postoperative pulmonary complications and in our study we have studied them and noted about how various reasons are associated in development of pulmonary complications. ${ }^{12}$ In our study 7 patients developed pneumonia after abdominal operations, which required ventilator support. These patients were associated with many other associated comorbidities, which reduces the respiratory functions and eventually leading to ventilatory support. All these patients were chronic smokers. Surgical trauma to the patient along with the duration of the anaesthesia given during surgery all play a major role in the development of the postoperative pulmonary complications. These patients underwent emergency major abdominal operations with the duration of anaesthesia of around 2.5 to 3.5 hours. Additional interventions like Chest Tube Insertion for Pleural Effusion and Tracheostomy were done to help the patients wean off from the ventilatory support. Out of 29 patients who needed ventilatory support, 8 patients gradually recovered. In the patients who recovered the other associated comorbidities were either less or absent, resulting in improvement in the respiratory functions after the abdominal operations. 


\section{CONCLUSION}

Postoperative pulmonary complications are the most challenging complications a surgeon has to deal with after abdominal surgeries.

Postoperative pulmonary complications depend on many factors related to the patient, surgeon and environment.

Pre-disposing factors are advanced age, high BMI, impaired preoperative cognitive function, co-morbid conditions like pre-existing COPD, cancer, MI, hypertension, DM or stroke, smoking, history of acute respiratory infection, ASA physical status, prolonged preoperative length of stay, duration of anaesthesia, surgical incision and longer duration of nasogastric tube.

The most common pulmonary complications after abdominal surgeries are pneumonia, atelectasis, pleural effusion, ARDS and lung collapse.

In our study, maximum number of pulmonary complications were seen in the age group of 55 - 74 years. Presence of nasogastric tube impairs the cough reflex and provides a more direct pathway for oropharyngeal bacteria to lungs, thus increasing respiratory tract infection.

Postoperative pneumonia is the most common pulmonary complication. In our study patients who had postoperative pulmonary complications $31.27 \%$ of patients suffered from pneumonia, $28.23 \%$ of people suffered from atelectasis and $24.70 \%$ of people suffered from pleural effusion.

Cigarette smoking is a significant preoperative risk factor. This effect is primarily related to the resulting chronic lung disease. In our study, the pulmonary complications following abdominal operations were seen more in patients who are smokers with a percentage of $63.41 \%$.

Prolonged surgery was also identified as significant predictors of postoperative pulmonary complications. In our study maximum pulmonary complications were seen with patients in whom surgical duration was between $2-3 \mathrm{hrs}$.

Postoperative pulmonary complications increase the morbidity and mortality significantly and add to the economical burden of the patient and his family due to a prolonged stay in the hospital. It can affect the outcome of surgery drastically. Proper pre- and post-operative pulmonary care, early mobilisation, appropriate anaesthetic technique and judicial use of antibiotics may be helpful in reducing the number of postoperative pulmonary complications.

\section{REFERENCES}

[1] Neto LJ, Thomson JC, Cardoso JR. Postoperative respiratory complications from elective and urgent/emergency surgery performed at a university hospital. J Bras Pneumol 2005;31(1):41-7.

[2] Denu ZA, Yasin MO, Melekie TB, et al. Postoperative pulmonary complications and associated factors among surgical patients. J Anesth Clin Res 2015;6:554.

[3] Canet J, Mazo V. Postoperative pulmonary complications. Minerva Anestesiol 2010;76(2):138-43.

[4] Graybill WS, Frumovitz M, Nick AM, et al. Impact of smoking on perioperative pulmonary and upper respiratory complications after laparoscopic gynaecologic surgery. Gynecol Oncol 2012;125(3):556-60.

[5] Nelson R, Edwards S, Tse B. Prophylactic nasogastric decompression after abdominal surgery. Cochrane Database Syst Rev 2007;(3):CD004929.

[6] Arozullah AM, Khuri SF, Henderson WG, et al. Development and validation of a multifactorial risk index for predicting postoperative pneumonia after major non-cardiac surgery. Ann Intern Med 2001;135(10):847-57.

[7] Brooks-Brunn JA. Predictors of postoperative pulmonary complications following abdominal surgery. Chest 1997;111(3):564-71.

[8] Jayr C, Matthay MA, Goldstone J, et al. Preoperative and intraoperative factors associated with prolonged mechanical ventilation. A study in patients following major abdominal vascular surgery. Chest 1993;103(4):1231-6.

[9] Bluman LG, Mosca L, Newman N, et al. Preoperative smoking habits and postoperative pulmonary complications. Chest 1998;113(4):883-9.

[10] Kanat F, Golcuk A, Teke T, et al. Risk factors for postoperative pulmonary complications in upper abdominal surgery. ANZ J Surg 2007;77(3):135-41.

[11] Smetana GW, Lawrence VA, Cornell JE, et al. Preoperative pulmonary risk stratification for noncardiothoracic surgery: systematic review for the American College of Physicians. Ann Intern Med 2006;144(8):581-95.

[12] Mathew JT, D’Souza GA, Kilpadi AB. Respiratory complications in postoperative patients. J Assoc Phys of India 1999;47(11):1086-8. 